\title{
Editorial: The Past, Present and Future of Risk Regulation
}

The year 2017 will go down in history as a particularly disruptive, uncomfortable year for the world we live in. Amid a few major, largely unexpected political events and ensuing geopolitical shifts, we sense that we are standing on the edge of a new era.

This is a time in which the core tenets of the past half-century - of representative democracy as the way forward, of free press as a key tool in holding our elected representatives accountable, of scientific method to identify what is true and what is not, and of unrestrained globalisation - are challenged. Although still largely fuzzy, a new world order is emerging. This is having a tangible impact on public policy, through a systematic questioning of the fact base upon which decision-making must take place. Organised manipulation of facts for political ends and the growing acceptance of conspiracy theories fuelled by 'fake news' are emergent trends of particular concern. According to the Oxford Dictionaries, 'post-truth' was the word of the year 2016, largely as a result of political campaigns in the USA and the UK that were successful despite or because of - their loose relationship with the 'facts'.

What is at stake is the very foundation of our scholarly and daily contributions to our societies. While countering these false narratives will require decisive action from political representatives, it is everyone's responsibility within the research community to provide a small yet decisive contribution.

It is against this backdrop that we would like to renew our commitment to the mission pursued by this journal since its very inception in 2010. That is to encourage a new type of research that will not only cross over the too-often sealed disciplinary boundaries of law, sociology, political science, risk analysis, economics, psychology and applied behavioural sciences, but also nudge each of us to bridge the gap between our own scholarly agenda and societal needs. Recent events and the challenges ahead not only proved this vision right (unfortunately), but they currently command us to leave the prototypical, academic ivory tower and engage more with our communities.

It is against this backdrop that 2017 marks the beginning of a new chapter in the life of the European Journal of Risk Regulation. As you can see, the pages of this journal are now published by the world's oldest publishing house: Cambridge University Press. Although significant for the future development of our Journal, this move takes place under the sign of continuity and change, to reflect the ever-expanding scope of risk regulation, both from a geographical and disciplinary perspective.

This is mirrored by the diverse community of scholars who accepted invitations to join our editorial board and those who agreed to maintain a role. We are indeed particularly pleased to rely on a superb, diverse, gender-balanced and committed community of junior and established scholars, as well as practitioners from virtually all over the world. 
To gain a glimpse of ongoing research and lay the basis for a future research agenda, we decided to devote our Cambridge inaugural issue to a broader yet personal reflection on the past, present and future of risk regulation. We asked the members of our editorial board to engage into an unprecedented exercise of scholarly self-reflection. They agreed to play the game, and contributed with concise opinion pieces framed around the following three questions:

1. Personal: What is your risk regulation story? How you got into this field. Why do you find it intellectually stimulating?

2. Descriptive: How would you define risk regulation research? What has been and what it is today?

3. Normative: What is the future of risk regulation? Your perspective, predictions, and scholarship agenda on what risk regulation research should be today.

The result is a bright, catchy collection of 20 insightful pieces. Our contributors invite the reader on a personal and peripatetic journey to the colourful and multi-faceted world of the regulation of risks.

In addition to this collection, this inaugural issue features EJRR traditional contents: research articles, reports, case commentaries and book reviews.

In line with its original mission, we want to offer our readers both deep, theoretical reflection and snappy reports on the latest developments in our field. While the former contents being often cited contribute to our journal's excellent rankings, the latter provide a unique resource for the classroom and keep practitioners abreast of changes well beyond blog reporting. The number of students and researchers who have embarked on masters' thesis and dissertations after having stumbled upon one of our pioneering reports covering new risk regulation themes is countless.

In their analysis of review clauses in EU legislation in the context of better lawmaking, Martin Weber, Nicholas Edwards and Stephan Huber provide a thorough examination of the review clauses that have been used in EU legislation since 2004. They show how these review clauses have been used across all policy areas in a rather inconsistent and semantically confusing way.

Karina Hester, Martin Mullins, Robert Ford and Finbarr Murphy provide a closer look of the Environmental Liability Directive's (ELD) impact on the nanotechnology sector. Their article addresses the potential environmental liability exposures of manufacturers and producers pursuant to the provisions of the ELD. It highlights the importance of the insurability of the liability risk, all of which bears significance for the sustainability of the industry.

In addition to these research articles, the issue covers some of the latest developments in various risk regulation sectors. From food to intellectual property over public health and regulatory impact assessments, our correspondents are keeping EJRR abreast of what the risk regulation community is currently kept busy with.

Finally, this inaugural issue publishes two case commentaries - the first one on dynamic IP addresses that can be considered as personal data, and the second on the labelling of individual portions of pre-packaged foods - and a book review. 
Let me seize once more the chance to welcome our new editorial board members and thank those who have been with us since the beginning of this journey.

Happy reading, Alberto ALEMANNO Editor-in-Chief, EJRR 